\title{
The erectile dysfunction as a cardiovascular risk factor
}

\author{
Nathan Artom, ${ }^{1}$ Giuliano Pinna ${ }^{2}$ \\ ${ }^{1}$ First Clinic of Internal Medicine, Department of Internal Medicine, University of Genoa School of Medicine, IRCCS AOU \\ San Martino-IST, Genoa; ${ }^{2}$ Internal Medicine, ASL AT, Asti, Italy
}

\begin{abstract}
Erectile dysfunction (ED), defined as the inability of the subject of the male gender to achieve and/or maintain an erection sufficient to permit satisfactory sexual intercourse, is a source of great discomfort for patients in everyday life. This condition has a high prevalence in the general population, although frequently underestimated in clinical practice. The purpose of this article is to review the epidemiology, the pathophysiology and the clinical features of this disease, emphasizing the importance of erectile dysfunction as an indicator of silent atherosclerotic disease.
\end{abstract}

\section{Introduction}

Erectile dysfunction (ED) is defined as the inability of the subjects of the male gender to achieve and/or maintain an erection sufficient to permit satisfactory sexual intercourse. ED is different from sexual dysfunction, which may also affect the female gender, and, according to World Health Organization definition, is the set of all those problems for which an individual is unable to participate in a sexual relationship as he would like.

ED is a rather common condition, known since ancient times, being cited also in ancient Egyptian papyri. ${ }^{1,2}$ However the statistics on its prevalence are not consistent, either because there are various grades of severity of $\mathrm{ED}$, or because it is difficult to quantify the data using not adequately validated questionnaires. In medical literature the best validated score is the simplified international index of erectile function (IIEF-5): 5

Correspondence: Nathan Artom, First Clinic of Internal Medicine, Department of Internal Medicine, University of Genoa School of Medicine, IRCCS AOU San Martino-IST Istituto Nazionale per la Ricerca sul Cancro, viale Benedetto XV 6, 16100 Genoa, Italy.

Mob.: +39.348.0025.220

E-mail: nat.artom@hotmail.it

Key words: erectile disfunction, cardiovascular risk.

Received for publication: 5 March 2014.

Accepted for publication: 2 June 2014.

This work is licensed under a Creative Commons Attribution NonCommercial 3.0 License (CC BY-NC 3.0).

(C) Copyright N. Artom and G. Pinna, 2014

Licensee PAGEPress, Italy

Italian Journal of Medicine 2014; 8:210-220

doi:10.4081/itjm.2014.500 questions on sexual activity are administered and the consequent possible scores range from 5 to 25 ; ED is classified into 5 categories: severe (5-7), moderate (811 ), mild to moderate (12-16), mild (17-21) and no ED (22-25).

Obviously ED is a condition related to age: a recent analysis of the International Committee for Consultation on Sexual Medicine Definitions/Epidemiology/Risk Factors for Sexual Dysfunction ${ }^{4}$ reported a prevalence of: $<40$ years $1-10 \%$; $40-59$ years $2-19 \%$; $60-69$ years $20-45 \%$; $>70$ years $50-100 \%$

In Italy a survey by Mirone et al. reported progressive values of $4.6 \%$ in men under 25 years and of $37.6 \%$ in men over 74 years; 5 the most severe form of ED affects about $12-13 \%$ of the entire male population.

In recent times, perhaps due to the pressure of the industry following the development of the phosphodiesterase inhibitors (PDE5-I), ED received greater emphasis. In medical literature the role of ED as an early indicator of atherosclerotic disease increased significantly (see below). In fact the penis is the only organ of the human body which, depending on its different functional status (flaccidity or erection), blood passes from pressure values of a few $\mathrm{mmHg}$, like a vein, to values around $100 \mathrm{mmHg}$, like an artery. For this reason penis functionality may become a marker of both cardiovascular and metabolic health.

\section{Physiology of erection}

Erotic stimuli (tactile, visual, olfactory) cause a series of pulses from the hypothalamus and midbrain areas that reach the corpora cavernosa through the peripheral nerves. This leads to a relaxation of muscles of the corpora cavernosa, a vasodilation and an increase in arterial flow. The final outcome is a traffic jam of the sinusoidal spaces, an increase of intracavernous pressure and an enlargement of the penis that 
causes a compression of the subtunical veins (the albuginea is relatively inelastic) and thus an obstacle to the flow (Figure 1). At cellular level the erotic stimulus induces a release of nitric oxide (NO), which modulates the activity of the smooth muscle cells of the corpus cavernosum. Subsequently NO stimulates the cytosolic enzyme guanylate cyclase to produce a second messenger, the cyclic guanosine monophosphate (cGMP). The cGMP causes a decrease in intracellular $\mathrm{Ca}^{++}$. Even prostaglandin E1 and vasoactive intestinal peptide activate the adenylyl cyclase that converts adenine triphosphate (ATP) into cyclic adenosine monophosphate, which binds a protein kinase: the final result is a decrease in the intracellular levels of $\mathrm{Ca}^{++}$. The reduction in intracellular $\mathrm{Ca}^{++}$leads to a re- laxation of the smooth muscle, an increase in arterial flow, and then the erection. After ejaculation there is a massive sympathetic discharge and release of vasoactive hormones, with a consequent arterial vasoconstriction, decreased flow, release of venous sinusoids and detumescence. ${ }^{6}$

\section{Erectile dysfunction and endothelial dysfunction}

The fundamental role of NO and, more generally, of the endothelium, which regulates vascular tone through a complex balance of vasoconstricting and vasodilating factors, is now well appreciated. In fact the

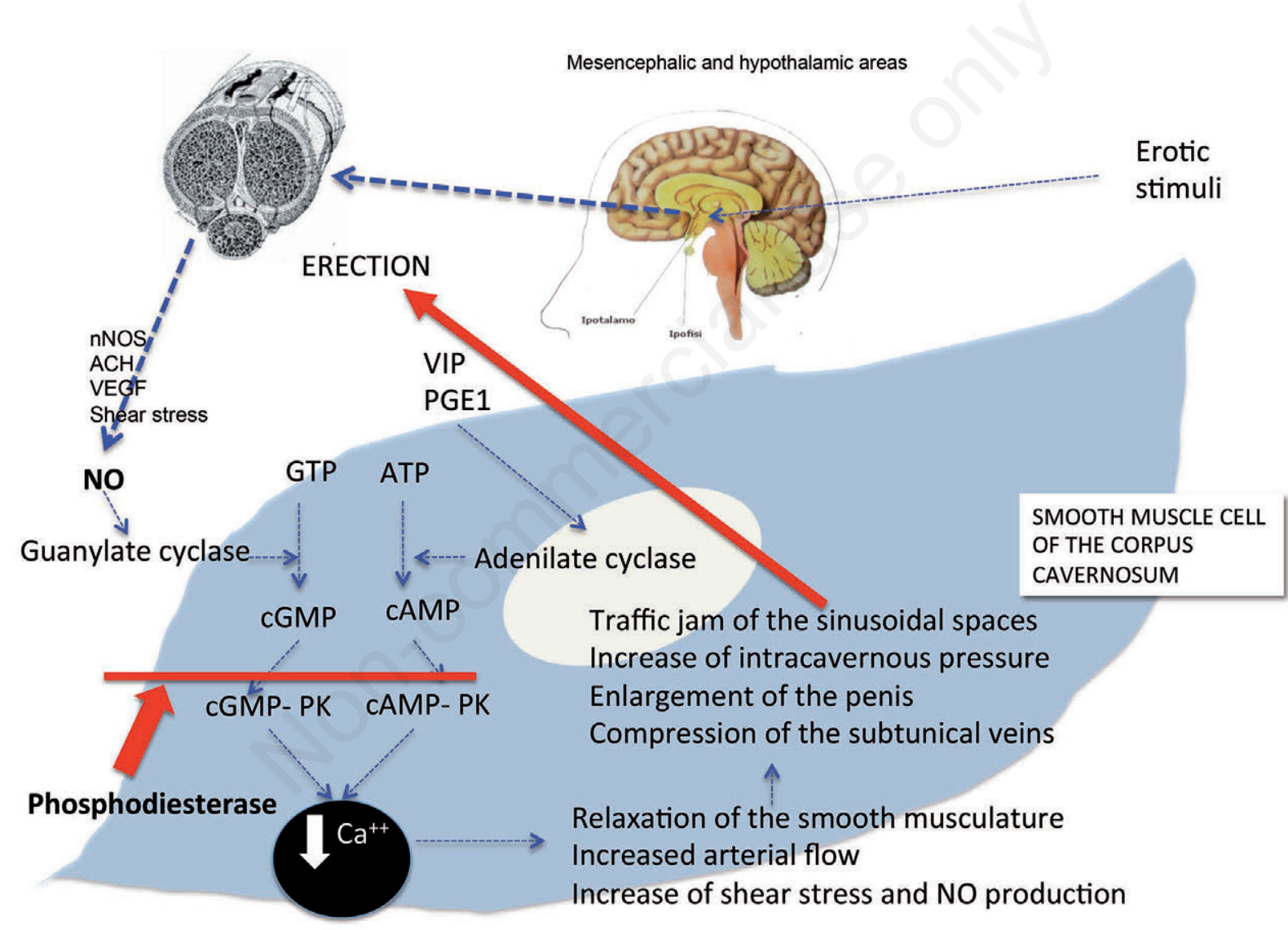

Figure 1. Erotic stimuli (tactile, visual, olfactory) cause a series of pulses from the hypothalamus and midbrain areas that reach the corpora cavernosa through the peripheral nerves. This leads to a relaxation of muscles of the corpora cavernosa, a vasodilation and an increase in arterial flow. The final outcome is a traffic jam of the sinusoidal spaces, an increase in intracavernous pressure and an enlargement of the penis that causes a compression of the subtunical veins (the albuginea is relatively inelastic) and thus an obstacle to the flow. At cellular level the erotic stimulus induces a release of nitric oxide (NO), which modulates the activity of the smooth muscle cells of the corpus cavernosum. Subsequently NO stimulates the cytosolic enzyme guanylate cyclase to produce a second messenger, the cyclic guanosine monophosphate (cGMP). The cGMP causes a decrease in intracellular $\mathrm{Ca}^{++}$. Even prostaglandin E1 (PGE1) and vasoactive intestinal peptide (VIP) activate the adenylyl cyclase that converts adenine triphosphate (ATP) into cyclic adenosine monophosphate (CAMP), which binds a protein kinase: the final result is a decrease of the intracellular levels of $\mathrm{Ca}^{++}$. The reduction in intracellular $\mathrm{Ca}^{++}$leads to a relaxation of the smooth muscle, an increase in arterial flow, and then the erection. After ejaculation there is a massive sympathetic discharge and release of vasoactive hormones, with a consequent arterial vasoconstriction, decreased flow, release of venous sinusoids and detumescence. 
endothelium produces endothelium-derived contracting factors (EDCF), a group of vasoconstricting, mitogenic and pro-thrombotic molecules; this production is secondary to the stimulation induced by acetylcholine, arachidonic acid, norepinephrine, prostaglandin H2, thrombin, high concentrations of potassium ions, physical forces (such as stretch and pressure). The EDCF include arachidonic acid metabolites, endothelin and angiotensin II. Endothelium is also able to produce endothelium-derived relaxing factors, such as NO, endothelium-derived hyperpolarizing factor, prostaglandins.

Other potential mechanisms involved in the development of endothelial dysfunction and subsequently leading to ED and coronary artery disease (CAD) include an increased peripheral sympathetic activity and vascular structural alterations, with consequent release of mediators of inflammation and a decrease in vasodilator activity.

Therefore it is clear that endothelial dysfunction has a main pathogenetic role in various atherosclerotic and vascular diseases: arterial hypertension, diabetic angiopathy, coronary vasospasm, heart failure. If erectile function is so deeply dependent on the endothelial function, we may easily realize how ED represents a marker of endothelial dysfunction, or, more extensively, of systemic vascular damage.
The artery size hypothesis explains why patients with $\mathrm{CAD}$ frequently report $\mathrm{ED}$ before $\mathrm{CAD}$ detection. ${ }^{7}$ According to this hypothesis, for a given atherosclerotic burden, the smaller penile arteries suffer obstruction earlier than the larger coronary arteries. The same concept holds true also in the case of nonobstructing atherosclerosis: since the smaller penile artery have a greater endothelial surface and erection requires a large degree of vasodilation to occur when compared with arteries in other organs, the same degree of endothelial dysfunction will be symptomatic in these smaller vessels but subclinical in the larger ones (i.e. coronary arteries). Therefore ED could be considered the prima ballerina of asymptomatic atherosclerotic artery disease. ${ }^{6}$ Figure 2 shows a recent pathogenetic hypothesis by Montorsi et al. ${ }^{8}$ when penile artery (diameter 1-2 $\mathrm{mm}$ ) presents established obstruction, the blood flow is not yet impeded in both coronary and brain arteries, even less in the peripheral circulation, and symptoms, occurring after a $50 \%$ obstruction, are therefore absent.

Not all authors agree with the pathogenetic mechanism proposed by Montorsi et al.: a study by Ponholzer et al., performed in 31 autopsies, assessed the prevalence and severity of penis atherosclerosis in relation to coronary and peripheral atherosclerosis and found that coronary and peripheral atherosclerosis

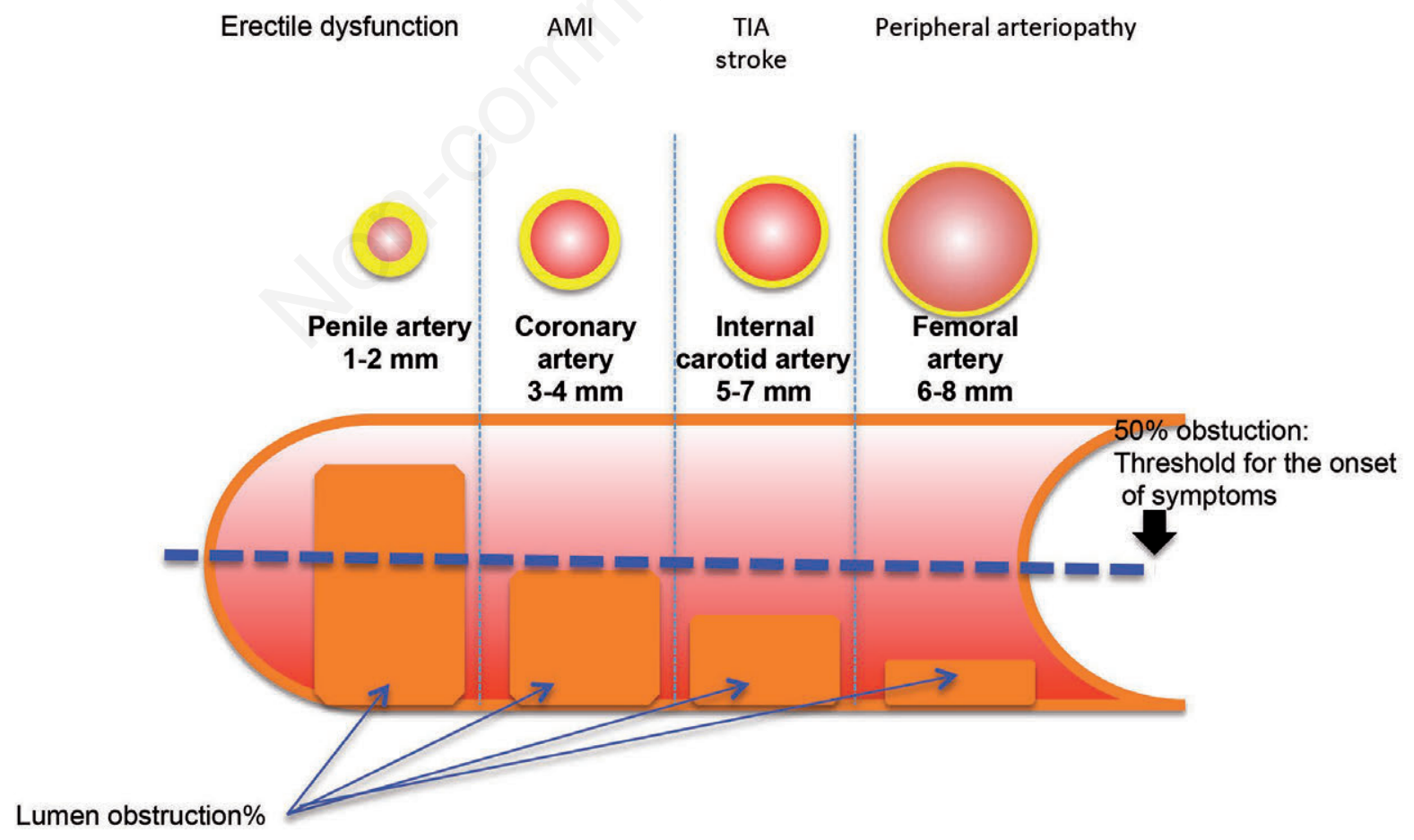

Figure 2. When penile artery (diameter 1-2 mm) presents established obstruction, the blood flow is not yet impeded in both coronary and brain arteries, even less in the peripheral circulation, and symptoms, occurring after a $50 \%$ obstruction, are therefore absent. AMI, acute myocardial infarction; TIA, transient ischemic attack. Modified from Montorsi et al., $2003 .{ }^{8}$ 
were present in 87.1 and $77.4 \%$ of the cases, whereas penile atherosclerosis was present only in $12.9 \%$ of the cases. In addition, the most important condition associated with penile atherosclerosis was diabetes mellitus $(\mathrm{P}=0.03){ }^{9}$

\section{Erectile dysfunction, cardiovascular and metabolic diseases}

Several risk factors are associated with a penile circulatory damage, such as atherosclerosis, hypertension, hyperlipidemia, cigarette smoking, diabetes. The Princeton Consensus Conference III identifies the ED as a strong predictor of cardiovascular disease and especially of coronary heart disease ${ }^{10}$ and defined cardiovascular risk as the risk of morbid events over a three to five year interval from the onset of ED in men without known cardiovascular disease ${ }^{11}$ Montorsi and collegues examined 300 patients with coronary artery disease documented by coronary angiography, and showed that 147 (49\%) had an ED and 99 (67\%) of these had ED before the coronary event. ${ }^{12}$

However in $30-40 \%$ of cases acute myocardial infarction (AMI) appears temporarily before ED. As already discussed, the explanation may be that for the appearance of AMI is a $50 \%$ stenosis, and patients who develop an AMI do not necessarily have extensive atherosclerosis at first diagnosis. This could explain also the coronary event during a normal sexual activity.

Other studies confirmed the association between $\mathrm{ED}$ and cardiovascular disease (CVD). ${ }^{13}$ In substudies of ONTARGET (Ongoing Telmisartan Alone and in Combination With Ramipril Global Endpoint Trial) and TRANSCEND (Telmisartan Randomized Assessment Study in ACE-Intolerant Subjects With Cardiovascular Disease) trials the ED is a powerful predictor of death from all causes and a composite endpoint of cardiovascular death, myocardial infarction, stroke, and heart failure. ${ }^{14}$ Incidentally, the antihypertensive treatment did not show any significant influence (either positive or negative) on ED.

Another study, with a 10-year follow-up of more than 1400 subjects who had regular partners and had no known coronary heart disease, found that a new coronary heart disease developed in $11 \%$ of men: $15 \%$ had AMI, 79\% angiographic abnormalities and 6\% sudden death. ${ }^{15}$

The recent COBRA (AssoCiatiOn Between eRectile dysfunction and coronary Artery disease $)^{16}$ trial tested the hypothesis that the degree of coronary artery disease in patients with ED differs according to the clinical presentation (acute or chronic ischemic heart disease) and according to the number of involved vessels (disease of one, two or three vessels): the prevalence of ED in patients with documented CAD was overall $47 \%$ (vs $24 \%$ of controls), but increased with the number of vessels involved. Furthermore both the severity and the duration of ED were predictive of the severity of CAD. In fact ED could be much less frequent in AMI patients with a single-vessel disease because the atherosclerotic burden is modest (sudden occlusion of a single non-stenotic plaque occurs in the absence of diffuse atherosclerosis) both in coronary and penile circulation. ${ }^{16,17}$ On the other hand patients with ED as the only atherosclerotic sign often conceal asymptomatic coronary artery disease. In a prospective angiographic study $19 \%$ of patients with ED suffered from silent CAD. ${ }^{18}$

In a meta-analysis of 14 prospective cohort studies involving 92,757 men followed for 6.1 years, the pooled relative rates (RRs) for ED were 1.19 [95\% confidence interval (CI), 0.97-1.46], 1.62 (95\% CI, 1.34-1.96), and 1.39 (95\% CI, 1.23-1.57) for CV mortality, AMI, and cerebrovascular events, respectively. The pooled RR for ED was 1.25 (95\% CI, 1.12-1.39) for all-cause mortality. ${ }^{19}$

Of course the ED is influenced by age, but it is peculiar that as predictor of CVD ED is more important in relatively young subjects compared to older ones. A study by Inman et al. noted that, when ED occurs in people under 60 years of age, it was associated with a sharp increase in the risk of future CV events, whereas in older subjects it had a lower prognostic effect. Even in patients under 49 years with ED, a risk of $\mathrm{CV}$ events was about 50 times higher than in those without ED. This means that the symptom is early, but also that the possibility of a long term prevention is present (Figure $\left.3^{15}\right) .{ }^{20,21}$

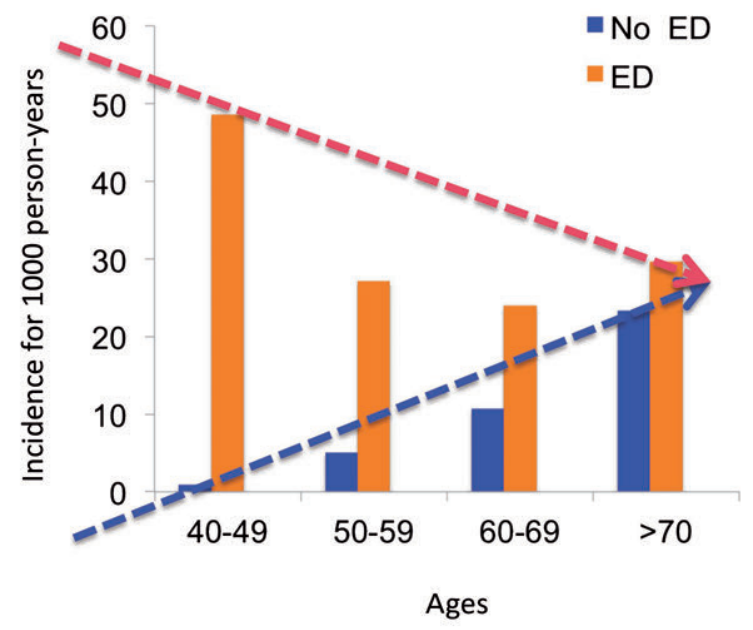

Figure 3. Incidence for $\mathbf{1 0 0 0}$ person-years of erectile dysfunction (ED) associated with coronary artery disease densities. In young subjects (40-49 years), the incidence of coronary artery disease in patients with $\mathrm{ED}$ is about 50 times higher than those without ED. Over the 70 years the values tend to be equivalent. Modified from Inman et al., 2009. ${ }^{15}$ 
ED should not be seen only as a marker of obstruction. Considering the activation of inflammatory and prothrombotic factors, we should also look at ED as an early warning of an impending acute event (mostly AMI) due to rupture of a subclinical plaque and hence the identification of a CV risk would ideally include the tests of plaque vulnerability. ${ }^{22,23}$

Recently, in addition to the prevalence of ED, the intensity of the sexual activity was also evaluated: an Italian study examined retrospectively the main determinants of CVD in relation to sexual activity and found that a higher frequency of sexual activity reduces the risk of CVD even after adjustment for other risk factors. Therefore it could be useful to identify subjects with mild to moderate ED as those with the lowest frequency of sexual intercourses: changing their sexual behavior may be an opportunity to reduce CV events. ${ }^{24}$

\section{Special conditions}

\section{Hypertension and erectile dysfunction}

Several studies have confirmed a significantly higher prevalence of ED in hypertensive patients.

The TOMHS study was the first large-scale study which found a relationship between arterial hypertension and ED, but it had excluded patients with diabetes and severe arterial hypertension and had postulated only one question on sexual activity. ${ }^{25}$ Further studies are needed in hypertensive patients to better define the increased incidence of ED in hypertensive subjects.

Some authors suggest a percent value of $68 \%{ }^{26,27}$

A study on 634 young or middle-aged (31-65 year) Greek subjects compared the prevalence of ED between hypertensive patients and normotensive subjects. ${ }^{28}$ The normotensive subjects had normal erectile function in $86 \%$ of cases, whereas those with hypertension in $65 \%$ of cases; among hypertensive patients $9 \%$ had severe ED, while among normotensives only $2 \%$. Preliminary data of a study by Artom et al. in 144 hypertensive patients (between 40 and 70 years of age) showed that $49 \%$ of subjects suffer from ED (Figure 4). ${ }^{28,29}$

From a pathophysiological point of view, hypertension can cause ED through a multitude of mechanisms including prolonged exposure to high systemic levels of blood pressure, endothelial dysfunction and circulating vasoactive substances (especially Ang II) leading to structural alterations of the penile arteries.

Of course antihypertensive drugs have a role on ED. Virtually all the antihypertensive drugs can affect it negatively, but those most commonly involved are the thiazide diuretics, $\beta$ blockers (with the possible exception of nebivolol, with its modulating activity on NO) $.{ }^{30} \mathrm{Cal}-$ cium channel blockers (CCB), $\alpha$ adrenergic blockers peripheral, ACE inhibitors, angiotensin receptor blockers (ARBs) are less commonly involved ${ }^{30}$ Furthermore ARBs may even have a beneficial effect. ${ }^{14,31}$

We remind that, during treatment with $\alpha$-blockers, PDE5-I, although not strictly contraindicated, should be used with great caution, because the risk of marked hypotension may be high. ${ }^{32}$

\section{Heart failure and erectile dysfunction}

The ED is quite common in patients with heart failure with further worsening of their quality of life. ${ }^{6}$

Heart failure can be a cause of ED, due to the neurohormonal activation, diuretic therapy, and depression. Improving the efficiency of the left ventricle
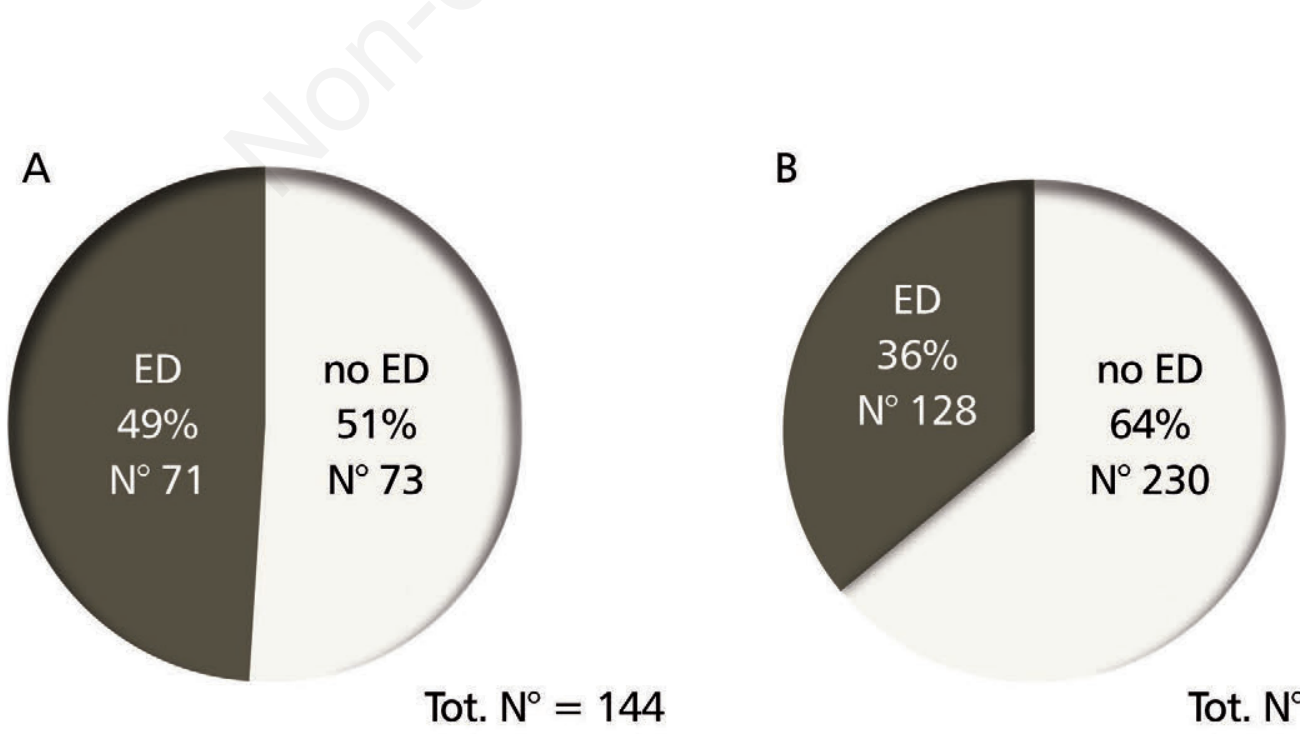

$$
\text { Tot. } \mathrm{N}^{\circ}=144
$$

Tot. $\mathrm{N}^{\circ}=358$

Figure 4. Erectile dysfunction (ED) in hypertensive subjects. A) Data from Artom et al., 2013. ${ }^{29}$ Age: 40-70 years; B) Data from Doumas et al., 2006. ${ }^{28}$ Age: 31-65 years. It is possible that the difference between the two statistics is due to the difference of age. 
could improve ED. However physical activity and ED are not always closely related. ${ }^{10,33,34}$

\section{Diabetes and erectile dysfunction}

Type 2 diabetes mellitus is the most important factor related to ED: this condition is present in $75 \%$ of diabetics subjects ${ }^{21}$ and there is a significant relationship between the severity of ED and the severity of the metabolic derangements. The reasons may be multiple: nerve impairment, ${ }^{35}$ atherosclerotic damage, ${ }^{36}$ alterations in the erectile tissue (degeneration of smooth muscle cells with abnormal collagen deposition), endothelial dysfunction. ${ }^{37}$ As a matter of fact diabetes exerts a fundamental role in endothelial dysfunction: high glucose levels induce the formation of advanced glycation end products (AGEs) that interfere with endothelial function through several mechanisms, including alterations in the generation of $\mathrm{NO}$, reactive oxygen species (ROS) and growth factors. AGEs are elevated in penile tissue of diabetic subjects and interfere with the production of $\mathrm{NO}$ directly activating phosphorylation of endothelial NO synthase (eNOS). The ROS formation increases oxidative stress AGEsassociated oxidative stress, with consequent alterations of the corpora cavernosa and an increase in lipid peroxidation, an up-regulation of superoxide anion $\left(\mathrm{O}_{2}{ }^{-}\right)$, and a decrease of antioxidants. ${ }^{38-40}$ Even more than in non-diabetic subjects, the ED predicts CAD in diabetic subjects; furthermore ED could be considered the most efficient predictor of silent CAD in the diabetic population, independently of metabolic control and ED severity. ${ }^{41}$ In 2036 diabetic Chinese subjects a significant prediction of coronary events was observed, even in the absence of symptoms, and it is interesting to note that in this trial ED is superior to microalbuminuria in predicting $\mathrm{CV}$ risk, and inferior only to macroalbuminuria. ${ }^{42}$ Finally Rosen et al. showed that diabetic subjects with best fitness levels have much less (about 40\%) ED. ${ }^{43}$

\section{Erectile dysfunction and dyslipidemia}

Various studies show that hypercholesterolemia induces a decrease of the normal vasoreactivity of the corpora cavernosa, in particular by lowering the local activity and bioavailability of eNOS/NO. The chances of developing a moderate ED in subjects 40 to 55 years are between $6.7 \%$ and $25 \%$, in close relationship with the high-density lipoprotein (HDL)-cholesterol values, while the chances to develop a severe ED in subjects with 56-70 years of age are between $0 \%$ and $16 \%$, with HDL-cholesterol levels from 90 to $30 \mathrm{mg} / \mathrm{dL}^{4}{ }^{44}$

The mechanism by which dyslipidemia may favor ED is probably related to the increase in oxidized lowdensity lipoprotein-cholesterol levels: they may inhibit the NO-mediated endothelium-dependent relaxation and increase the contraction of vascular smooth muscle cells. ${ }^{45}$

Also the decrease in HDL-cholesterol and the increase in triglycerides may have adverse effects on the contractile response and on vascular smooth muscle relaxation, although we must recognize that the role of triglycerides is actually controversial. ${ }^{46,47}$

A indirect measure of the relationship between dyslipidemia and ED is given by the benefical role of statins. ${ }^{48,49}$ However the STED (Simvastatin Treatment for Erectile Dysfunction) trial found no significant differences in the ED between simvastatin and placebo. ${ }^{50}$

\section{Obstructive sleep apnea syndrome and erectile dysfunction}

The relationship between ED and obstructive sleep apnea syndrome (OSAS) is now clear; according to the American Urological Association (AUA) 2011, ED should always be sought in patients with OSAS. These are the conclusions of a study that evaluated the link between ED and OSAS in 870 middle-aged males of Law enforcement cardiac screening program. This study, which is the largest published to date, demonstrates an independent association between ED and OSAS. ${ }^{51} \mathrm{Sev}-$ eral mechanisms have been proposed to explain this association: sleep deprivation which can lead to a decrease in testosterone levels during the night, hypoxia which can increase the levels of endothelin compromising the penile vasodilatation and the erection.

\section{The problem of testosterone}

Testosterone $(\mathrm{T})$ is the primary male sex hormone but is also produced by female endocrine glands. It is converted to $17 \beta$-estradiol by aromatase in many tissues, including vascular smooth muscle cells and adipose tissue, which is one of the major sources of estrogens. In obesity the formation of $17 \beta$-estradiol may be an important cause of feminization in males and may increase the risk of estrogen-sensitive cancers in obese women.

Low levels of T are associated with ED (with a concomitant decrease of libido) and to an increased $\mathrm{CV}$ risk.

However about its role on CV risk, although endogenous levels seem to have protective effects, testosterone therapy (TT), especially as abuse (in some countries it is regarded as erythropoietin), have negative effects. This is not a minor problem, because the anabolic effects of the TT are widely proposed, in particular in the elderly, where it may improve muscle mass, bone mineral density, mood, cognitive capacities, metabolic parameters, and erectile function. This is confirmed by a retrospective analysis performed in 384 patients undergoing prostate biopsy between September 2007 and December 2009.52 
Experimental data have attributed antiarrhythmic properties to $T$, because it decreases the duration of the action potential, the early depolarization and the QTc interval, ${ }^{53-55}$ as well as cardioprotective properties (it reduces the amplitude of a myocardial infarction modulating myocardial K-ATP channels, ${ }^{56,57}$ and vasodilatory properties..$^{58-60}$

It could also improve lipid and glucidic metabolism. ${ }^{61,62}$ However, according to other researchers, TT could be dangerous: it can cause vasoconstriction and inflammation, ${ }^{63}$ hypertension, ${ }^{64}$ interventricular septum, ${ }^{65}$ AMI, coronary spasm or thrombosis. ${ }^{66,67}$

Also the data about atherosclerosis are conflicting, ${ }^{68-70}$ as well as those on diabetes (although in this case it seems that a poorly controlled diabetes can cause a low testosterone level, and not the opposite). ${ }^{71}$ An extensive review of the literature (from 1970 to 2013) by Ruige and colleagues ${ }^{72}$ demonstrated that a low level of $\mathrm{T}$ is linked to hypertension, dyslipidemia, atherosclerosis, arrhythmia, thrombosis, endothelial dysfunction and left ventricular dysfunction with a rather modest relationship with $\mathrm{CV}$ morbidity/mortality. However the same authors did not find that TT, able to restore normal levels, induces a true benefit on cardiovascular disease, although there is no clear evidence of the contrary (specific adverse effects of TT): the doubts about the true advantages still remain. ${ }^{72,73}$ In a trial of the Veteran's Administration health care system in more than 8000 men with low $\mathrm{T}$ levels $(<300 \mathrm{ng} / \mathrm{dL})$ and documented coronary disease, TT was associated with an increased risk of adverse events (hazard ratio $1.29,95 \% \mathrm{CI}, 1.04$ to 1.58 ). The absolute rate of events was $19.9 \%$ in the group not treated with T $v s 25.7 \%$ in the TT group, with an absolute risk difference of $5.8 \%$ ( $95 \% \mathrm{CI},-1.4 \%$ to $13.1 \%) 3$ years after coronary artery angiography. ${ }^{74}$

A group of Canadian researchers hypothesized genetic causes, which could lead to different responses in patients: sex steroids dilate the coronary arteries but in hypertensive subjects, for example, a decrease in vasodilatory effects can be observed. This anomaly is attributed to the action of $\mathrm{T}$ on vascular muscle cells of hypertensive subjects, through genomic and nongenomic mechanisms, which determine the modulation of the associated cellular events, thereby leading to further worsening of hypertension. ${ }^{75}$ These authors found that in vascular smooth muscle cells of male animals, T regulates cell processes, such as the phosphorylation of non-receptor tyrosine kinase, c-src, which mediate contraction and vascular hypertrophy, key events contributing to the increased vascular resistance in hypertension. They also found an increased production of ROS in response to $\mathrm{T}$ in vascular smooth muscle cells of hypertensive animals compared to normotensive ones.

In essence, the endogenous $\mathrm{T}$ would have a more protective value in part due to its conversion to $17 \beta$ estradiol by aromatase, while the exogenous hormone, especially at high doses, would have an hypertensive effect. Thus, particularly in elderly frail subjects, aggressive TT could increase the risk of CV events. ${ }^{76-78}$ There is enough agreement among the various scientific societies that $\mathrm{T}$ levels greater than $350 \mathrm{ng} / \mathrm{dL}$ do not require replacement therapy, whereas this approach may benefit patients with $\mathrm{T}$ levels $<230$ ng/dL. ${ }^{10}$ However adverse cardiovascular effects of TT cause much debate in the scientific community: the US Food and Drug Administration (FDA) is now officially investigating the potential that FDA-approved testosterone products increase the risk of serious adverse cardiovascular outcomes. ${ }^{79}$

\section{Critical points}

- The essential doubt remains, i.e. that low T may be an epiphenomenon related to poor health conditions, rather than a causal risk factor (see above the discussion about diabetes).

- TT, following strict clinical criteria, can be useful. The criticisms to this approach are not few but there are also studies questioning the safety of TT present bias: the already mentioned review by Ruige et al., although not particularly favorable to TT, states that studies have shown, in many cases, bias about design or interpretation, not allowing to draw definitive conclusions. ${ }^{72}$

- This is precisely the point: the results of the available studies cannot settle the controversy yet, and we feel the lack of appropriately designed randomized trials with adequate length.

\section{Consensus in the scientific community}

- It is necessary to use TT with great caution in men with a history of heart failure, due to the risk of fluid retention.

- There are diseases in which TT is absolutely contraindicated: prostate or breast cancer; palpable prostate nodules or hardened prostate or prostatespecific antigen $>0.4 \mathrm{ng} / \mathrm{mL}$ (or $0.3 \mathrm{ng} / \mathrm{mL}$ in men at high risk for prostate cancer); hematocrit $>50 \%$ (testosterone increases hematocrit).

\section{Treatment of erectile dysfunction in patients with cardiovascular diseases}

First of all we must treat cardiovascular risk factors already at middle age: this could decrease the risk of both ED and coronary heart disease, as demonstrated in the Rancho Bernardo Study, which followed a community of males aged between 39 and 69 years for 25 years. ${ }^{42}$

According to the Third Princeton Consensus Panel 
Table 1. Properties of the various phosphodiesterase inhibitors.

\begin{tabular}{lccc}
\hline & Sildenafil & Vardenafil & Tadalafil \\
\hline Dosage & $\begin{array}{c}25,50,100 \mathrm{mg} \\
\text { Maximum dose } 100 \mathrm{mg} / \mathrm{die}\end{array}$ & $\begin{array}{c}2.5,5,10,20 \mathrm{mg} \\
\text { Maximum dose } 20 \mathrm{mg} / \text { die }\end{array}$ & $\begin{array}{c}2.5,5.10 .20 \mathrm{mg} \\
\text { Maximum dose 20 mg/die }\end{array}$ \\
\hline Onset & $30-60 \mathrm{~min}$ & $30 \mathrm{~min}$ & $45 \mathrm{~min}$ \\
\hline Side effects & Headache, flushing, dyspepsia & Headache, flushing, dyspepsia & Flushing, myalgia \\
\hline Contraindications & $\begin{array}{c}\text { Nitrate containing compounds, } \\
\text { recent CV events, optic neuropathy, } \\
\alpha \text {-blockers }\end{array}$ & $\begin{array}{c}\text { As for sildenafil, but also type 1 } \\
\text { or 3 antiarrhythmics }\end{array}$ & As for sildenafil \\
\hline Food and alcohol interaction & $\begin{array}{c}\text { Interacts with food, } \\
\text { not alcohol interaction }\end{array}$ & $\begin{array}{c}\text { Interacts with food, } \\
\text { not alcohol interaction }\end{array}$ & No food or alcohol interaction \\
\hline
\end{tabular}

$\mathrm{CV}$, cardiovascular.

it is necessary to implement an approach integrating multiple cardiometabolic aspects: accepted these principles, in clinical practice there is not a standard behavior to be observed. ${ }^{8}$

\section{After a cardiovascular event, what is the suggested behavior for the patient, with regards to sexual activity?}

We can stratify patients for the CV risk: i) in patients at low risk we can encourage the resumption of sexual activity, treating the ED with the warning of avoiding PDE5-I in patients treated with nitrates; ii) in patients at intermediate risk, after an adequate period of follow-up, you have to re-evaluate the risk in order to re-classify subjects at low or high risk; iii) in patients at high risk you must first stabilize the cardiovascular situation disease before a resumption of sexual activity and the initiation of the treatment for ED is suggested.$^{80}$ Of course it is important to keep in mind the affective situation of the patient. Sexual activity with the usual partner is different to the sexual activity with a new partner, in which there is usually a greater emotional involvement. Additional stressors (large meals or alcohol) are also important. ${ }^{81}$

Finally, the risk of death during sexual activity is low if the patient is able to perform moderate physical activity (5-6 METS) without ischemia (1 MET=consumption of $250 \mathrm{~mL} / \mathrm{min}$ of $\mathrm{O}_{2}$ ).

\section{Use of phosphodiesterase inhibitors in subjects with cardiac disease}

Overall PDE5-I are well tolerated. We remind only that sildenafil is highly influenced by the amount of food (especially fatty food) and alcohol, while vardenafil only by alcohol. Table 1 summarizes the properties of the various PDE5-I.
Except, of course, nitrates, can you use the other cardiac drugs in combination with phosphodiesterase inhibitors?

According to the consensus conference, ${ }^{10}$ there is no reason to avoid heparin, $\beta$-blockers, CCB, RASinhibitors, diuretics, tranquillizers, aspirin and other antiplatelet agents. About $\alpha$-blockers we stress what mentioned previously: although not strictly contraindicated, they should be used with great caution because the risk of severe hypotension may be high. ${ }^{32}$ However, even using nitrates, the PDE-I can be taken, but with great caution and avoiding nitrates $24 \mathrm{~h}$ before and after taking PDE-I.

\section{Conclusions}

Although underestimated, there is a close relationship between ED and cardiovascular risk and the ED can be considered an early indicator of cardiovascular damage. It is likely that hypertension plays a negative role in the ED, but diabetes is the disease most frequently associated with ED. Recently, it has been demonstrated that obesity and obstructive sleep apnea are associated with ED. Investigating the possible presence of ED in patients with cardiovascular risk factors may be a useful tool in clinical practice for the early detection of the atherosclerotic vascular disease.

\section{References}

1. Smith GE. Papyrus ebers. English translation. Chicago, IL: Ares Publishers; 1974.

2. Shah J. Erectile dysfunction through the ages. BJU Int 2002;90:433-41.

3. Rhoden EL, Telöken C, Sogari PR, Vargas Souto CA. The use of the simplified international index of erectile function (IIEF-5) as a diagnostic tool to study the preva- 
lence of erectile dysfunction. Int J Impot Res 2002; 14:245-50.

4. Lewis RW, Fugl-Meyer KS, Corona G, et al. Definitions/epidemiology/risk factors for sexual dysfunction. J Sex Med 2010;7:1598-607.

5. Mirone V, Ricci E, Gentile V, et al. Determinants of erectile dysfunction risk in a large series of italian men attending andrology clinics. Eur Urol 2004;45:87-91.

6. Manolis A, Doumas M. Sexual dysfunction: the 'prima ballerina' of hypertension related quality-of-life complications. J Hyperten 2008;26:2074-84.

7. Vlachopoulos C, Jackson G, Stefanadis C, Montorsi P. Erectile dysfunction in the cardiovascular patient. Eur Heart J 2013;34:2034-46.

8. Montorsi P, Montorsi F, Schulman CC. Is erectile dysfunction the 'tip of the iceberg' of a systemicvascular disorder. Eur Urol 2003;44:352-4.

9. Ponholzer A, Stopfer J, Bayer G, et al. Is penile atherosclerosis the link between erectile dysfunction and cardiovascular risk? An autopsy study. Int J Impot Res 2012;24:137-40.

10. Nehra A, Jackson G, Miner M, et al. The Princeton III consensus recommendations for the management of erectile dysfunction and cardiovascular disease. Mayo Clin Proc 2012;87:766-78.

11. Muneer A, Kalsi J, Nazareth I, Arya M. Erectile dysfunction. BMJ 2014;348:g129.

12. Montorsi F, Briganti A, Salonia A, et al. Erectile dysfunction prevalence, time of onset and association with risk factors in 300 consecutive patients with acute chest pain and angiographically documented coronary artery disease. Eur Urol 2003;44:360-5.

13. Shabsigh R, Perelman MA, Lockart DC, et al. Health issues of men: prevalence and correlates of erectile dysfunction. J Urol 2005; 174:662-7.

14. Böhm M, Baumhäkel, Teo K, et al. Erectile dysfunction predicts cardiovascular events in high-risk patients receiving telmisartan, ramipril, or both. The ONgoing Telmisartan Alone and in combination with Ramipril Global Endpoint Trial/Telmisartan Randomized AssessmeNt Study in ACE-INtolerant Subjects with cardiovascular Disease (ONTARGET/TRANSCEND) Trials. Circulation 2010;121:1439-46.

15. Inman BA, Sauver JL, Jacobson DJ, et al. A populationbased, longitudinal study of erectile dysfunction and future coronary artery disease. Mayo Clin Proc 2009; 84:108-13.

16. Montorsi P, Ravagnani PM, Galli S, et al. Association between erectile dysfunction and coronary artery disease. Role of coronary clinical presentation and extent of coronary vessels involvement: the COBRA trial. Eur Heart J 2006;27:2632-9.

17. Jackson G. Erectile dysfunction: a marker of silent coronary artery disease. Eur Heart J 2006;27:2613-4.

18. Vlachopoulos C, Rokkas K, Ioakeimidis N, et al. Prevalence of asymptomatic coronary artery disease in men with vasculogenic erectile dysfunction: a prospective angiographic study. Eur Urol 2005;48:996-1002.

19. Vlachopoulos C, Terentes-Printzios D, Ioakeimidis N, et al. Prediction of cardiovascular events and all-cause mortality with erectile dysfunction. A systematic review and meta-analysis of cohort studies. Circ Cardiovasc Qual Outcomes 2013;6:99-109.
20. Miner M. Men's health in primary care: an emerging paradigm of sexual function and cardiometabolic risk. Urol Clin N Am 2012;39:1-23.

21. Miner M, Seftel AD, Nehra A, et al. Prognostic utility of erectile dysfunction for cardiovascular disease in younger men and those with diabetes. Am Heart J 2012;164:21-8.

22. Vlachopoulos C, Aznaouridis K, Ioakeimidis N, et al. Unfavourable endothelial and inflammatory state in erectile dysfunction patients with or without coronary artery disease. Eur Heart J 2006;27:2640-8.

23. Thompson IM, Tangen CM, Goodman PJ, et al. Erectile dysfunction and subsequent cardiovascular disease. JAMA 2005;294:2996-3002.

24. Corona G, Rastrell G, Monami M, et al. Frequency of sexual activity and cardiovascular risk in subjects with erectile dysfunction: cross-sectional and longitudinal analyses. Andrology 2013;1:864-71.

25. Grimm R, Gregory A. Grandits GA, et al. Long-term effects on sexual function of five antihypertensive drugs and nutritional hygienic treatment in hypertensive men and women: treatment of mild hypertension study (TOMHS). Hypertension 1997;29:8-14.

26. Mittawae B, El-Nashaar AR, Fouda A, et al. Incidence of erectile dysfunction in 800 hypertensive patients: a multicenter Egyptian national study. Urology 2006; 67:575-8.

27. Burchardt M, Burchardt T, Baer L, et al. Hypertension is associated with severe erectile dysfunction. J Urol 2000;164:1188-91.

28. Doumas M, Tsakiris A, Douma S, et al. Factors affecting the increased prevalence of erectile dysfunction in Greek hypertensive compared with normotensive subjects. J Androl 2006;27:469-77.

29. Artom N, Pende A, Musso NR, et al. Prevalence of the erectile dysfunction in a population of hypertensive male subjects (multicentre study of the SIIA section Piemonte-Liguria-Valle d'Aosta). High Blood Press Cardiovasc Prev 2013;20:222.

30. Viigimaa M, Doumas M, Vlachopoulos C, et al. Hypertension and sexual dysfunction: time to act. J Hypertens 2011;29:403-7.

31. Chen Y, Cui S, Lin H, et al. Losartan improves erectile dysfunction in diabetic patients: a clinical trial. Int J Impoot Res 2012;24:217-20.

32. Kloner RA, Jackson G, Emmick JF, et al. Interaction between the phosphodiesterase 5 inhibitor, tadalafil and 2 $\alpha$-blockers, doxazosin and tamsulosin in healthy normotensive men. J Urol 2004;172:1935-40.

33. Baraghoush A, Phan A, Willix RD Jr, Schwarz ER. Erectile dysfunction as a complication of heart failure. Curr Heart Fail Rep 2010;7:194-201.

34. Apostolo A, Vignati C, Brusoni D, et al. Erectile dysfunction in heart failure: correlation with severity, exercise performance, comorbidities, and heart failure treatment. J Sex Med 2009;6:2795-805.

35. Krane R, Goldstein I, Saenz de Tejada I. Impotence. N Engl J Med 1989;321:1648-59.

36. Andersson KE, Wagner G. Physiology of penile erection. Physiol Rev 1995;75:191-236.

37. Saenz de Tejada I. Diabetic penile neuropathy. J Clin North Am 1988;15:17-22.

38. Costa C, Virag R. The endothelial-erectile dysfunction 
connection: an essential update. J Sex Med 2009; 6:2390-404.

39. Bivalacqua TJ, Usta MF, Kendirci M, et al. Superoxide anion production in the rat penis impairs erectile function in diabetes: influence of in vivo extra-cellular superoxide dismutase gene therapy. J Sex Med 2005; 2:187-97.

40. Tuncayengin A, Biri H, Onaran M, et al. Cavernosal tissue nitrite, nitrate, malondialdehyde and glutathione levels in diabetic and non-diabetic erectile dysfunction. Int J Androl 2003;26:250-4.

41. Gazzaruso C, Giordanetti S, De Amici E, et al. Relationship between erectile dysfunction and silent myocardial ischemia inapparently uncomplicated type 2 diabetic patients. Circulation 2004;110:22-6.

42. Fung MM, Bettencourt R, Barrett-Connor E. Heart disease risk factors predict erectile dysfunction 25 years later: the Rancho Bernardo Study. JACC 2004;43: 1405-11.

43. Rosen RC, Wing RR, Schneider S, et al. Erectile dysfunction in type 2 diabetic men: relationship to exercise fitness and cardiovascular risk factors in the Look AHEAD trial. J Sex Med 2009;6:1414-22.

44. Feldman HA, Goldstein I, Hatzichristou DG, et al. Impotence and its medical and psychosocial correlates: results of the Massachusetts Male Aging Study. J Urol 1994;151:54-61.

45. Kim SC. Hyperlipidemia and erectile dysfunction. Asian J Androl 2000;2:161-6.

46. Chowienczyk PJ, Watts GF, Wierzbicki AS, et al. Preserved endothelial function in patients with severe hypertriglyceridemia and low functional lipoprotein lipase activity. J Am Coll Cardiol 1997;29:964-8.

47. Lewis TV, Dart AM, Chin-Dusting JP. Endothelium-dependent relaxation by acetylcholine is impaired in hypertriglyceridemic humans with normal levels of plasma LDL cholesterol. J Am Coll Cardiol 1999;33:805-12.

48. Herrmann HC, Levine LA, Macaluso J Jr, et al. Can atorvastatin improve the response to sildenafil in men with erectile dysfunction not initially responsive to sildenafil? Hypothesis and pilot trial. Results J Sex Med 2006;3:303-8.

49. Solomon H, Samarasinghe YP, Feher MD, et al. Erectile dysfunction and statin treatment in high cardiovascular risk patients. Int J Clin Pract 2006;60:141-5.

50. Mastalir ET, Carvalhal GF, Portal VL. The effect of simvastatin in penile erection: a randomized, double-blind, placebo-controlled clinical trial (Simvastatin treatment for erectile dysfunction-STED TRIAL). Int J Impot Res 2011;23:242-8.

51. Berookhim B. Erectile dysfunction is independently associated with sleep apnea in a large population of middle-aged men. In: Proc. of the 106th Annual Meeting of the American Urological Association (AUA), 2011 May 14-19, Washington, DC, USA. Berlin: Springer; 2002. pp 182-191.

52. Garcia-Cruz E, Piqueras M, Huguet J, et al. Hypertension, dyslipidemia and overweight are related to lower testosterone levels in a cohort of men undergoing prostate biopsy Int J Impot Res 2012;24:110-3.

53. Bai CX, Kurokawa J, Tamagawa M, et al. Nontranscriptional regulation of cardiac repolarization currents by testosterone. Circulation 2005;112:1701-10.
54. Brouillette J, Rivard K, Lizotte E, Fiset C. Sex and strain differences in adult mouse cardiac repolarization: importance of androgens. Cardiovasc Res 2005;65:148-57.

55. Liu J, Tsang S, Wong TM. Testosterone is required for delayed cardio-protection and enhanced heat shock protein 70 expression induced by preconditioning. Endocrinology 2006;147:4569-77.

56. Tsang S, Wu S, Liu J, Wong TM. Testosterone protects rat hearts against ischaemic insults by enhancing the effects of $\alpha(1)$-adrenoceptor stimulation. Br J Pharmacol 2008;153:693-709.

57. Das B, Sarkar C. Similarities between ischemic preconditioning and $17[\beta]$-estradiol mediated cardiomyocyte KATP channel activation leading to cardioprotective and antiarrhythmic effects during ischemia/reperfusion in the intact rabbit heart. J Cardiovasc Pharmacol 2006; 47:277-86.

58. Deenadayalu VP, White RE, Stallone JN, et al. Testosterone relaxes coronary arteries by opening the largeconductance, calcium-activated potassium channel. Am J Physiol Heart Circ Physiol 2001;281:H1720-7.

59. O'Connor EK, Ivey JR, Bowles DK. Differential effects of androgens on coronary blood flow regulation and arteriolar diameter in intact and castrated swine. Biol Sex Differ 2012;3:10.

60. Jones RD, English KM, Jones TH, Channer K. Testosterone-induced coronary vasodilatation occurs via a non-genomic mechanism: evidence of a direct calcium antagonism action. Clin Sci 2004;107:149-58.

61. Filippi S, Vignozzi L, Morelli A, et al. Testosterone partially ameliorates metabolic profile and erectile responsiveness to PDE5 inhibitors in an animal model of male metabolic syndrome. J Sex Med 2009;6:3274-88.

62. Jackson FL, Hutson JC. Altered responses to androgen in diabetic male rats. Diabetes 1984;33:819-24.

63. Herring MJ, Oskui PM, Hale SH, Kloner RA. Testosterone and the cardiovascular system: a comprehensive review of the basic science literature. J Am Heart Assoc 2013;2:e000271

64. Angell P, Chester N, Green D, et al. Anabolic steroids and cardiovascular risk. Sports Med 2012;42:119-34.

65. Hartgens F, Kuipers H. Effects of androgenic-anabolic steroids in athletes. Sports Med 2004;34:513-54.

66. Fanton L, Belhani D, Vaillant F, et al. Heart lesions associated with anabolic steroid abuse: comparison of postmortem findings in athletes and norethandrolone-induced lesions in rabbits. Exp Toxicol Pathol 2009;61:317-23.

67. Fisher M, Appleby M, Rittoo D, Cotter L. Myocardial infarction with extensive intracoronary thrombus induced by anabolic steroids. Br J Clin Pract 1996;50:222-3.

68. Bruck B, Brehme U, Gugel N, et al. Gender-specific differences in the effects of testosterone and estrogen on the development of atherosclerosis in rabbits. Arterioscler Thromb Vasc Biol 1997;17:2192-9.

69. Hatakeyama H, Nishizawa M, Nakagawa A, et al. Testosterone inhibits tumor necrosis factor-alpha-induced vascular cell adhesion molecule-1 expression in human aortic endothelial cells. FEBS Lett 2002;530:129-32.

70. Ng MK, Quinn CM, McCrohon JA, et al. Androgens upregulate atherosclerosis-related genes in macrophages from males but not females: molecular insights into gender differences in atherosclerosis. J Am Coll Cardiol 2003;42:1306-13. 
71. Ballester J, Domõnguez J, Munoz MC, et al. Tungstate treatment improves Leydig cell function in streptozotocin-diabetic rats. J Androl 2005;26:706-15.

72. Ruige JB, Ouwens DM, Kaufman JM. Beneficial and adverse effects of testosterone on the cardiovascular system in men. J Clin Endocrinol Metab 2013;98:4300-10.

73. Romanelli F. Il testosterone influenza il sistema cardiovascolare nel maschio? AME News 2013;43:1-2. Available from: http://www.associazionemediciendocrinologi. it/materiali/news/amenews/ame news-43-novembre2013.pdf

74. Vigen R, O’Donnell CI, Barón AE, et al. Association of testosterone therapy with mortality, myocardial infarction, and stroke in men with low testosterone levels. JAMA 2013;310:1829-36.

75. Chignalia AZ, Schuldt EZ, Camargo LL, et al. Testosterone induces vascular smooth muscle cell migration by NADPH oxidase and c-src-dependent pathways. Hypertension 2012;59:1263-71.

76. Basaria S, Coviello AD, Travison TG, et al. Adverse events associated with testosterone administration. N Engl J Med 2010;363:109-22.
77. Xu L, Freeman G, Cowling BJ, Schooling CM. Testosterone therapy and cardiovascular events among men: a systematic review and meta-analysis of placebo-controlled randomized trials. BMC Med 2013;11:108.

78. Finkle WD, Greenland S, Ridgeway GK, et al. Increased risk of non-fatal myocardial infarction following testosterone therapy prescription in men. PLoS One 2014; 9:e85805.

79. Food and Drug Administration. FDA Drug Safety Communications: FDA evaluating risk of stroke, heart attack, and death with FDA-approved testosterone products. January 31, 2013. Available from: http://www.fda.gov/ Drugs/DrugSafety/ucm383904.htm

80. DeBusk R, Drory Y, Goldstein R, et al. Management of sexual dysfunction in patients with cardiovascular disease: recommendations of the Princeton consensus panel. Am J Cardiol 2000;86:62F-8F.

81. Cheitlin MD, Hutter AM Jr, Brindis RG, et al. AHA/ACC expert consensus document. Use of sildenafil (Viagra) in patients with cardiovascular disease. American College of Cardiology/American Heart Association. J Am Coll Cardiol 1999;33:273-82. 